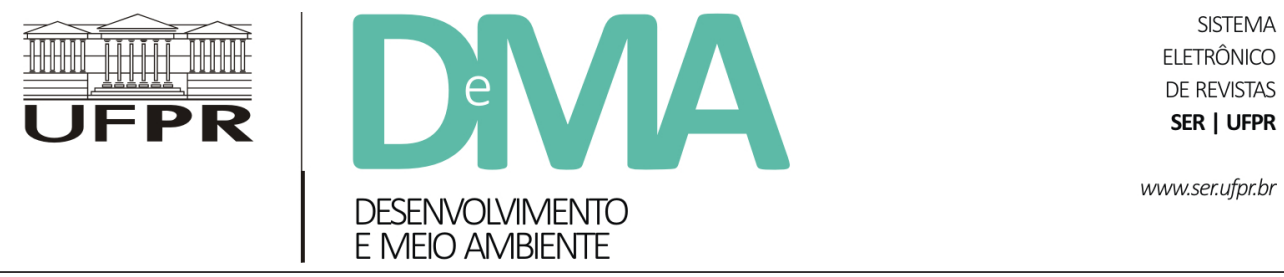

\title{
¿Resistencia o propuesta? Situación y perspectivas de la producción ovina agroecológica en la Región Metropolitana de Uruguay
}

\author{
Resistência ou proposta? Situação e perspectivas da produção \\ agroecológica de ovinos na Região Metropolitana do Uruguai
}

\section{Resistance or proposal? Situation and perspectives of agroecological sheep production in the Uruguayan Metropolitan Region}

\author{
Rodrigo GARCÍA FERREIRA ${ }^{1^{*}}$ \\ ${ }^{1}$ Universidad de la República, Montevideo, Uruguay. \\ *E-mail de contacto: rgarcia@pim.edu.uy
}

Artículo recibido el 28 de junio, 2017, versión final aceptada el 12 de marzo, 2018.

RESUMEN: En los últimos años la producción ovina dio señales de crecer en la Región Metropolitana (RM) uruguaya y aparecer como una posibilidad para los agricultores familiares de dicha región. En particular una producción ovina basada en el manejo agroecológico se plantea como alternativa para estos agricultores. El presente estudio analiza la situación de la producción ovina en la RM, especialmente aquella basada en un manejo agroecológico, buscando identificar y evaluar esta propuesta productiva como posible alternativa de resistencia para la agricultura familiar de la Región. Para ello se analizan sus principales posibilidades y limitantes. Se realizó investigación documental y bibliográfica para analizar las transformaciones de realidad agraria y producción ovina de la Región en los últimos años. Se implementaron entrevistas a técnicos y productores con vínculo y experiencia en el tema, así como un Grupo de discusión. En el trabajo se evidencia que el crecimiento que tuvo la producción ovina en los últimos quince años en la RM se dio especialmente en pequeños establecimientos de agricultores familiares, contrastando con el desarrollo histórico de esta producción en el país. En relación a la producción ovina agroecológica, existen experiencias incipientes que generan interés en consumidores y algunos productores, aunque es casi nulo su espacio en la investigación y las políticas públicas, con muy poco conocimiento acumulado en el tema. Avanzar en la investigación, la formación y principalmente en el debate sobre la necesidad de cambios en los modelos tecnológicos en el 
interior de las organizaciones de agricultores familiares, aparecen como movimientos necesarios para hacer de la producción ovina agroecológica una alternativa viable.

Palabras clave: producción ovina agroecológica; agroecología; agricultura familiar.

RESUMO: Nos últimos anos, a produção de ovinos mostrou sinais de crescimento na Região Metropolitana (RM) do Uruguai e aparece como possibilidade para os agricultores familiares na Região. Em particular, a produção de ovinos baseada no manejo agroecológico aparece como alternativa para esses agricultores. Este estudo analisa a situação da produção de ovinos na RM, especialmente aquela de base agroecológica, visando identificar e avaliar essa proposta como uma possível alternativa de resistência para agricultores familiares na Região. Para isso, suas principais possibilidades e limitações foram analisadas. Pesquisa documental e bibliográfica foram realizadas para analisar as transformações da realidade agrária e na produção de ovinos na Região nos últimos anos. Entrevistas com técnicos e produtores com ligação e experiência com o tema foram implementadas, assim como um grupo de discussão. Em nosso trabalho fica evidente que o crescimento da produção de ovinos nos últimos quinze anos na RM esteve especialmente baseado nos pequenos agricultores familiares locais, em contraste com o desenvolvimento histórico dessa produção no país. Em relação à produção agroecológica de ovinos, existem experiências incipientes que geram interesse em consumidores e alguns produtores, mas seu espaço é quase nulo na pesquisa e nas políticas públicas, com pouco conhecimento acumulado sobre o assunto. Fomentar a pesquisa, formação e, principalmente, o debate sobre a necessidade de mudanças em modelos tecnológicos no interior das organizações de agricultores familiares aparecem como movimentos necessários para tornar a produção agroecológica de ovinos uma alternativa viável.

Palavras-chave: produção agroecológica de ovinos; agroecologia; agricultura familiar.

ABSTRACT: In recent years, sheep production has shown signs of growing in the Uruguayan Metropolitan Region (RM) and emerge as a possibility for family farmers in that region. In particular, sheep production based on agroecological management is proposed as an alternative for these farmers. The present study analyzes the situation of sheep production in the RM, especially that based on agroecological management principles, seeking to identify and evaluate this production proposal as a possible alternative of resistance to family farmers in the Region. To this end, its main possibilities and limitations were analyzed. Documentary and bibliographical research was done in order to analyze the transformations in the agrarian reality and in sheep production in the Region in recent years. Interviews were conducted with technicians and farmers involved with and with experience in the field, and a discussion group was implemented as well. In this research, it becomes clear that the growth of sheep production in the last fifteen years in the RM occurred especially in small properties of family farmers, contrasting with the historical development of this production in the whole country. In relation to agroecological sheep production, there are incipient experiences that spark the interest of consumers as well as some producers, but its space in research and public policies is almost null, with very little accumulated knowledge. The instigation of research, education and above all of the debate about the need for changes in technological models inside the organizations of family farmers emerge as necessary moves to once again make agroecological sheep production a viable alternative.

Keywords: agroecological sheep production; agroecology; family farming. 


\section{Introducción}

La producción ovina durante más de un siglo jugó un papel muy importante en Uruguay, donde la lana fue uno de los principales productos de exportación. Históricamente esta producción la desarrollaron medianos y grandes productores de las regiones Norte y Este del país sobre grandes extensiones de praderas naturales, manejando razas especializadas para la producción de lana y en asociación con ganadería vacuna, con baja incorporación de tecnologías y sobre la base de trabajo asalariado (Moraes, 2003; Finch, 2005; Barrán, 2007; Nahum, 2007).

Pero desde la década de 1990, al desaparecer en forma abrupta las condiciones favorables del mercado internacional de la lana, el rubro comenzó una caída fuerte y permanente que se mantiene hasta nuestros días. Durante los años siguientes la cantidad total de ovinos del país pasó de las 25 millones de cabezas, en 1991, a menos de 7 millones en 2015 (INAC, 2006; 2016). La superficie dedicada a esta producción también cayó vertiginosamente, pasando de representar el $41 \%$ de la superficie agropecuaria uruguaya en 1990, a ser tan solo el $9 \%$ del total en el año 2000 y apenas el 3\% en 2011 (MGAP, 2005; 2010; 2015).

Sin embargo durante los últimos quince años en la Región Metropolitana (RM) del país (Departamentos de Montevideo y Canelones) se ha dado un proceso a la inversa. Tanto la cantidad de agricultores de esta Región dedicados principalmente a la producción ovina, como la superficie destinada a la misma, aumentaron a más del doble entre los años 2000 y 2011 (MGAP, 2001; 2013). Los ovinos comenzaron a presentarse como una alternativa para los agricultores de la RM, algo que antiguamente no sucedía en una Región que desde inicios del Siglo XX se ha caracterizado por ser la principal proveedora de alimentos de granja (hortifruticultura, cerdos y aves) para el mercado local, sobre la base de agricultores familiares de pequeña escala, (Piñeiro, 1985; 1991; Finch, 2005). Los cambios en la coyuntura del mercado de carne ovina (con precios internacionales favorables y posibilidad de acceso a mercados de alta demanda), junto a las mejores condiciones de la zona Sur del país para la cría intensiva y el engorde de corderos (Ganzábal et al., 2001; SUL, 1999), así como los incentivos surgidos desde la industria frigorífica para la integración de los productores a cadenas agro-exportadoras de carne ovina (Kremer, 2010; Acosta \& Arretche, 2010), han sido factores importantes para esto. Pero también han sido determinantes otros procesos más profundos que se viven en la RM.

Los modelos de desarrollo implementados en el país desde la segunda mitad del Siglo pasado, bajo el paraguas de la apertura de los mercados y el estímulo de la intensificación en el caso de la horticultura, con altos niveles de insumos externos e inversión y gran dependencia de las agroindustrias, generó que gran parte de los agricultores de la Región no consiguieran adaptarse a este modelo. Esto, sumado a la permanente caída del precio de los productos y el aumento en los costos de energía e insumos (Piñeiro, 1985; Oyhantçabal, 2010; Dogliotti et al., 2012), desembocó en un fuerte proceso de desaparición de agricultores familiares en la RM y migración a centros urbanos.

Entre 1990 y 1999 desapareció la tercera parte de los sistemas hortícolas del Sur (Bacigalupe \& Salvo, 2007), tendencia que continuó entre los años 2000 y 2011 en la RM, con la pérdida de un 30\% 
de estos agricultores más pequeños (MGAP, 2001; 2013). La propuesta para aquellos que se mantuvieron era adoptar el modelo de intensificación y especialización, basado en el uso de productos químicos de síntesis industrial para fertilizar y controlar plagas, buscando aumentar la producción para obtener similares ingresos familiares. La consecuencia fue una mayor presión sobre los suelos, previamente ya deteriorados, con aumento de la degradación y contaminación de los bienes naturales de la Región (Bacigalupe \& Salvo, 2007; García de Souza et al., 2011). Como resultado, esta representa la zona del país con mayor incidencia y severidad de la erosión de sus suelos, inclusive con grandes áreas desertificadas (Gonzalez Idiarte, 2008; Garcia de Souza et al., 2011; Díaz, 2013). A esto se suma que en sus principales cuencas hidrológicas se detectan muy elevados niveles de nutrientes (principalmente fósforo y nitrógeno), que causan fenómenos de eutrofización antrópica (Goyenola et al., 2011; 2013), incluyendo algunas de las principales fuentes de agua potable de la RM como son la Cuenca del Río Santa Lucía para Montevideo y la de la Laguna del Cisne para la costa de Canelones. La gravedad del tema y sus vínculos con las transformaciones productivas de estos territorios en los últimos años (principalmente con el avance de la agricultura extensiva), ha llevado a la toma de medidas en ambas cuencas por parte de autoridades nacionales y departamentales, restringiendo las actividades productivas que allí se desarrollan y desencadenando distintos conflictos ambientales.

Es esta coyuntura de degradación de los bienes naturales y fuertes dificultades para la horticultura es que la producción ovina aparece como alternativa interesante para los agricultores familiares de la Región y sus organizaciones. A su vez el conflicto ambiental emergente puede presentarse como una oportunidad para avanzar en la construcción de propuestas que integren a los ovinos dentro de un manejo agroecológico de los agroecosistemas.

El presente estudio se propone analizar la situación actual y posible papel de la producción ovina agroecológica (POA) en la Región Metropolitana uruguaya dentro del contexto de desaparición de sus agricultores familiares, identificar los principales factores que juegan a favor y en contra de su desarrollo, así como las posibles perspectivas de esta propuesta. Para ello se recurrió al análisis documental y bibliográfico, buscando analizar las transformaciones de la realidad agraria y la producción ovina de la Región en los últimos años. Se realizaron entrevistas a agricultores y técnicos vinculados a la producción ovina en la RM. También se conformó un Grupo de discusión (Canales \& Peinado, 1995) de agricultores entorno al tema. Tal investigación se realizó en el marco del trabajo que viene desarrollando el Programa Integral Metropolitano (PIM) de la Universidad de la República (UdelaR) en la RM en conjunto con organizaciones de agricultores familiares y agroecológicos, como lo son la Comisión Nacional de Fomento Rural (CNFR) y la Red de Agroecología del Uruguay (RAU).

El trabajo se organiza en cinco apartados. En el primero se intenta vincular los procesos de explotación y desaparición que ha sufrido la agricultura familiar, particularmente la uruguaya, con sus distintas estrategias de resistencia y cómo se vincula con ello la agroecología. A continuación se busca el acercamiento a una definición local de producción ovina agroecológica (POA), que surge del proceso de investigación en conjunto con los sujetos directamente involucrados. El tercer apartado presenta una síntesis de la situación actual de 
la POA, especialmente para la RM. Posteriormente se abordarán los principales factores que juegan a favor y en contra del desarrollo de esta propuesta. Finalmente se presentan algunos de los posibles desafíos que se tienen por delante.

\section{Resistencia de la agricultura familiar y agroecología}

\subsection{Formas de explotación de la agricultura familiar}

La desaparición de los agricultores familiares uruguayos viene siendo un proceso constante durante los últimos sesenta años. Entre 1960 y 2011 la cantidad de productores agropecuarios del país se redujo casi a la mitad, principalmente por la pérdida de agricultores familiares pequeños (MGAP, 1983; 2013). Puede encontrarse la explicación de esta tendencia permanente a la destrucción de la agricultura familiar y su diferenciación social, en las distintas formas de explotación que sufre este grupo social.

En primer lugar varios autores plantean que este proceso propio de la existencia y el avance de las relaciones mercantiles en el campo. Foladori (1986), al analizar el campesinado, señala que tal como propuso Marx (2012), la producción de mercancías con destino a ser realizadas en el mercado está sujeta a la ley del valor. La magnitud del valor de las mercancías que cada productor envía al mercado estará dada en un primer momento por el tiempo de trabajo que dedique para su producción. Para el global de la economía mercantil ello se traducirá en el tempo de trabajo socialmente necesario (TTSN) para hacerlo, esto es, aquella magnitud de trabajo que la sociedad destina en promedio para la producción de ese tipo de mercancía (Marx, 2012). Al momento de igualarse las mercancías en el mercado, todos los productores recibirán un precio similar, correspondiente a este TTSN. Pero habrá productores que dedicarán más tiempo para producir un tipo de mercancía (por encima del TTSN) y otros que dedicarán menos tiempo. Por lo tanto esas diferencias llevarán a que aquellos que dediquen más tiempo que la media estarán transfiriendo un excedente de trabajo a aquellos que produzcan por debajo del TTSN. En la medida que las condiciones estructurales y tecnologías de los productores no se modifiquen, comienzan a sentarse las bases para un constante proceso de diferenciación social, que producirá que unos pocos agricultores se enriquezcan y una mayoría se empobrezca, con la progresiva pérdida de sus medios de producción y posterior proletarización (Foladori, 1986).

Pero esto se profundiza con el avance del capitalismo en el campo. A lo anterior se suman otros mecanismos cuya centralidad está en la extracción de los excedentes del trabajo campesino y de agricultores familiares, por parte de las clases dominantes. Para Deere \& De Janvry (1979, apud Piñeiro, 1985) existen tres mecanismos principales por los cuales los campesinos son expoliados de sus excedentes: mediante la renta de la tierra (derivada de la propiedad privada de la misma), mediante los impuestos (recaudados por el Estado de diferentes formas) y mediante los mercados (siendo la forma más común e incluye los mercados de productos, de trabajo y del dinero). Para estos autores dichos mecanismos de extracción de excedentes son centrales para explicar la descomposición de la agricultura familiar.

A su vez, en la medida que las relaciones capitalistas avanzan y se territorializan, se profun- 
dizan otros mecanismos de explotación. Por un lado sucede lo que Harvey (2005) llama acumulación por desposesión, al extenderse y profundizarse las relaciones capitalistas en nuevas esferas de la vida, como sucede al imponerse las relaciones sociales capitalistas en territorios que hasta ese momento se estructuraban en torno a la producción y reproducción campesina. Fernandes (2012) señala que estos avances desencadenan conflictos y disputas territoriales entre el capital y los campesinos, propias de la imposibilidad de realización de una clase social en el territorio de otra clase. Para el ámbito rural uruguayo, Oyhantçabal (2013) propone tres territorios que surgirían de estas disputas: el territorio del agronegocio, producto de la territorialización del capital transnacional; el territorio del capital local monopolizado y/o articulado al agronegocio, donde los capitalistas locales disputan con el agronegocio (por momentos asociados, por momentos enfrentados) la apropiación de la plusvalía generada por el trabajo asalariado; y el territorio de la agricultura familiar subordinada por el capital, principalmente a través de su integración vertical y dependiente de los complejos agroindustriales.

A pesar de todas estas formas de explotación, la destrucción de la agricultura familiar no sucede de manera lineal, sino en forma contradictoria, incluso con momentos donde otras fuerzas sociales pueden favorecer su reproducción y frenar la tendencia a su desaparición, incluso facilitando su crecimiento. Un claro ejemplo para el caso uruguayo está en el papel que jugó el Estado durante la primera mitad del Siglo XX, dándole un rol fundamental a la agricultura familiar dentro del desarrollo capitalista de la época y estimulando su crecimiento y desarrollo (Piñeiro, 1985). Aquí podría usarse la noción de contra-tendencias (Tommasino, 2001), como aquellas fuerzas que se oponen a la tendencia principal de la diferenciación social. Ejemplo de estas podrían ser las políticas agrarias que protegen o estimulan la agricultura familiar, así como aquellas de reforma agraria y colonización.

\subsection{Formas de resistencia de la agricultura familiar}

Ante estas tendencias, los agricultores familiares y campesinos responden con diferentes estrategias o formas de resistencia. En este sentido, Piñeiro (1985) entiende que los mecanismos de extracción de excedentes son centrales en las posibilidades de reproducción o destrucción del campesinado, por lo que define esta resistencia como aquellas formas de acción, colectivas o individuales, ejercidas por miembros de una clase subordinada, que limitan la extracción de excedentes o que son capaces de afectar la intensidad con la cual el excedente es extraído. Las diferentes formas que tome la resistencia de los agricultores familiares ante la extracción de excedentes dependerán de la intensidad de esa extracción y de la presión y/o represión que sobre ellos ejercen las clases dominantes. Entre las formas colectivas de resistencia aparecen principalmente las organizaciones sociales y políticas que representan los intereses de agricultores familiares y campesinos (Piñeiro, 1985), pero también podrían incluirse aquellas propuestas que buscan resolver colectivamente las principales restricciones estructurales de sus sistemas de producción (Narbondo et al., 2010; García Ferreira et al., 2011; Oreggioni, 2011). Dentro de las formas individuales de resistencia se encuentran principalmente la desmercantilización parcial (disminuyendo la compra-venta 
de mercancías y aumentando la proporción del autoconsumo dentro de lo producido) y la búsqueda de ingresos extra-prediales (Piñeiro, 1985). También podrían incluirse aquí las estrategias que Carvalho (2013) entiende necesarias para que el campesinado disminuya su nivel de subordinación con relación al capital: retomar la capacidad y la voluntad política de producir alimentos para su autoconsumo, modificando así su matriz de consumo familiar; cambiar su matriz tecnológica de producción rumbo a propuestas que eviten los altos niveles de dependencia que tienen los éstos agricultores respecto la agroindustria capitalista.

\subsection{Agroecología como resistencia}

Partiendo de lo anteriormente y tomando las definiciones de Sevilla Guzmán (2015), la agroecología puede ser entendida entonces como un conjunto de formas o estrategias de resistencia del campesinado y de la agricultura familiar, que combina tanto acciones individuales como colectivas. Este autor plantea que la agroecología surge como respuesta de los campesinos al avance del capitalismo en la agricultura, ante lo cual se presenta inicialmente como una forma de resistencia individual, con un primer intento de desmercantilización de su vida y su producción de alimentos. Luego avanza en la búsqueda de formas alternativas de producción y circulación de los alimentos, principalmente a nivel local, expresándose entonces como forma colectiva de resistencia al modelo tecnológico hegemónico y al avance del capital sobre el territorio, procurando la construcción de otras relaciones técnicas (basadas en el manejo ecológico de los agroecosistemas) y sociales (entre los agricultores y con los consu- midores). Es aquí donde se desarrolló el diálogo entre el saber popular y el saber científico, para la construcción de propuestas superadoras (Sevilla Guzmán, 2015).

\subsection{Agroecología como propuesta}

Pero luego la resistencia colectiva se transformó en propuesta política de enfrentamiento al avance del capital y de construcción de propuestas alternativas a partir de los movimientos sociales populares. La disputa entonces no ocurre solamente en la ocupación del territorio agrario, sino también en el ámbito político y en la lucha contra la hegemonía que propone el modelo del agronegocio (Sevilla Guzmán, 2015). En ese sentido que para los movimientos sociales la agroecología puede constituirse al mismo tiempo una herramienta para resistir y confrontar el avance del capital sobre la agricultura y un conjunto de alternativas concretas de producción de alimentos y de realización de la vida en el campo, donde la centralidad no sea la producción de mercancías y el lucro (Grossi Rodrigues, 2014). Pinheiro Machado \& Pinheiro Machado Filho (2014) agregan que para lograr eso, la propuesta deberá ser capaz de confrontar al agronegocio también a mayor escala y que para lograrlo es fundamental la conjunción entre el saber tradicional de los agricultores con el conocimiento científico y tecnológico generado en los últimos años.

\section{La producción ovina agroecológica}

Tanto en Uruguay como en el resto de América, no encontramos una definición específica de 
lo que son producción ovina agroecológica (POA) o manejo agroecológico de ovinos.

Entre las primeras dificultades para acercarse a una definición de POA están las diferencias, no siempre explicitadas en la teoría o la práctica, entre los conceptos de agricultura orgánica y agroecológica. La propuesta de la agricultura orgánica tiene un fuerte foco en aspectos técnico-agronómicos y metodológicos, buscando desarrollar prácticas agrícolas que reduzcan al mínimo el uso de insumos externos, especialmente evitando los fertilizantes y abonos sintéticos, con la aplicación de métodos que reduzcan al mínimo la contaminación del aire, el suelo y el agua (OMS \& FAO, 2007). Si bien las formas de organización social están consideradas, su meta principal es lograr altos niveles de salud de las personas y el ambiente, de productividad agropecuaria y de calidad de los alimentos, lo que se sintetiza en las "Directrices para la producción, elaboración, etiquetado y comercialización de alimentos producidos orgánicamente" del Codex Alimentarius (OMS \& FAO, 2007). Por otro lado, la agroecología puede entenderse como una propuesta que tiene como objetivo y objeto de estudio "el manejo ecológico de los recursos naturales a través de formas de acción social colectiva para el establecimiento de sistemas de control participativo y democrático, en los campos de la producción y circulación", involucrando las dimensiones ecológica y técnico-productiva; la socioeconómica y cultural; y la política (Sevilla Guzmán, 2012). Aquí las propuestas técnicas y productivas se entienden y cobran sentido en conjunto con las formas de organización social popular. Es por ello que, en una definición de producción ovina agroecológica, estos aspectos deberían ser integrados.
Uno de los lugares donde se avanzó en definir y sistematizar la propuesta de producción ovina ecológica fue España, debido en gran parte al lugar histórico de la producción ovina en algunas varias de ese país, así como a la existencia de normativas europeas que regulan y estimulan la producción ganadera ecológica (García Trujillo \& Rebollo Vergara, 2014). Justamente una de las principales influencias para las definiciones españolas sobre ésta producción se encuentra en el "Directrices..." del Codex Alimentarius, con un foco importante en el control de la calidad de los alimentos con destino a mercados internacionales.

Sin embargo, a pesar de esas posibles referencias, la realidad uruguaya difiere mucho de la europea, por lo que una primera necesidad de éste trabajo fue acercarse a una definición propia de POA que partiera de la visión de los propios agricultores involucrados y sus organizaciones, adecuándose a su realidad y necesidades. En esta sección se sintetiza una primera aproximación, surgida tanto del análisis de la normativa y documentos existentes a nivel nacional, como de las entrevistas y el grupo focal. Se destacan las definiciones y normativas del Programa de Certificación Participativa en Red para la producción ecológica de la Red de Agroecología del Uruguay (RAU) como uno de los insumos centrales (RAU, 2006). La RAU es el principal espacio donde articulan agricultores ecológicos, consumidores, procesadores y distribuidores de alimentos, organizaciones no gubernamentales e instituciones que apuestan al desarrollo de la agroecología en el país (Gómez Perazzoli \& Galeano, 2006) y es la encargada de implementar estos sistema de certificación. 


\section{1. ¿Qué se entiende por producción ovina agroecológica?}

Si bien el Programa de Certificación antes mencionado no presenta una definición específica sobre qué es la POA o la producción ganadera agroecológica, en sus definiciones y normativas existe una serie de criterios y bases generales que permiten aproximarse. Lo primero es cumplir con los principios generales sobre los cuales se sustenta la RAU: avanzar hacia sistemas de producción económicamente viables, ambientalmente sustentables y socialmente justos; preservar la biodiversidad y los bienes naturales; promover la soberanía alimentaria; promover que los procesos de producción y circulación reviertan la situación actual de concentración de la riqueza, estimulando principalmente canales de comercialización que vinculen directamente productores y consumidores; fortalecer procesos organizativos de agricultores y consumidores; atacar las desigualdades de género, edad y cualquier tipo de discriminación; contribuir a la dignificación de los trabajadores y asegurar el acceso a sus derechos para los integrantes de las familias de agricultores y trabajadores, especialmente los niños. Pero hay otra serie de aspectos más específicos que deberían integrar la POA:

a) que asegure el bienestar animal, considerando sus necesidades fisiológicas, de comportamiento y de salud

Los animales deberán tener acceso adecuado al agua, el abrigo y el alimento, permitiendo cubrir las necesidades biológicas y etológicas de la especie. Esto no solo implica que su manejo general será en pastoreo al aire libre, donde los encierros no podrán ser permanentes (García Trujillo \& Rebollo Vergara, 2014), sino que se deberá constar con instalaciones adecuadas para ello.

\section{b) que las razas animales utilizadas estén adaptadas a las condiciones ambientales de la región y del agroecosistema}

Se busca trabajar con razas adaptadas a las condiciones climáticas, de manejo y a la alimentación de la región. Es por ello que la tendencia estará en procurar razas locales, que generalmente presentarán menos problemas de enfermedades, buenas características de crianza dentro de las condiciones de alimentación local y que a pesar de sus menores índices de productividad, generalmente resultan en productos de buena calidad (García Trujillo \& Rebollo Vergara, 2014).

\section{c) que esté integrada al resto de las} producciones del agroecosistema, contribuyendo en su diversidad y desarrollo conjunto

Debería desarrollarse de forma integrada y complementaria con los demás procesos productivos del agroecosistema, lo que para la RM implica especialmente la integración en rotación con las producciones vegetales intensivas, especialmente con la horticultura. Las interacciones entre cultivos y animales pueden ser diversas y generalmente provechosas para éste tipo de sistemas (Devendra \& Thomas, 2002). La integración también busca contribuir a la recirculación de nutrientes del agroecosistema, tanto por la deposición directa de heces 
y orina en el pastoreo directo, como por el compostaje de materia acumulada en los confinamientos nocturnos de los animales (Figueiredo et al., 2012; Thorne \& Tanner, 2002).

\section{d) que no dependa estructuralmente de insumos externos al agroecosistema}

Dado que el mercado de insumos es uno de los fuertes mecanismos de expoliación de excedentes del trabajo de estas familias, evitar la dependencia de insumos externos al agroecosistema tiene importantes implicaciones económicas para ellas. Pero también implicancias ecológicas, porque generalmente éstos insumos provienen de la síntesis industrial y no solo generan fuertes impactos en los procesos biológicos, sino también su uso constante genera fuerte dependencia de los agroecosistemas, afectando los ciclos biológicos que allí se desenvuelven (Pinheiro Machado, 2011).

\section{e) que la alimentación sea en base a} pasturas, producidas principalmente en el propio establecimiento de forma agroecológica y sin organismos genéticamente modificados (OGM)

La búsqueda debería estar en que las principales entradas al sistema provengan de la energía solar, de la lluvia, del aire y de la actividad biológica del suelo (Pinheiro Machado, 2011) a través de la mejora en la captación de energía solar producto de una buena combinación pasto/animal/rotación de cultivos y del estímulo de la biocenosis (desarrollo dinámico de la vida del suelo). f) Que no degrade los bienes naturales, especialmente suelo, agua y pasturas naturales

Deberá realizarse con un manejo adecuado del pastoreo que además de ofrecer alimento de calidad y en cantidad, favorezca la presencia de especies forrajeras nativas o adaptadas a cada agroecosistema. Al mismo tiempo debería manejarse una dotación animal acorde al agroecosistema, evitando especialmente sobrecargas que favorezcan la degradación de las pasturas y del suelo.

\section{g) que no utilice agrotóxicos, realizando un} manejo sanitario basado en la prevención y y priorizando el uso de la terapéutica natural o alternativa

No usar agrotóxicos, tanto en la producción vegetal como en la animal, además de evitar la dependencia de insumos externos, busca evitar los efectos negativos que tienen esas sustancias en los procesos biológicos del agroecosistema. Para el caso del control parasitario en ovinos, está demostrado el efecto negativo que tienen algunos antihelmínticos (en particular las ivermectinas) sobre insectos benéficos como moscas y escarabajos coprófagos (Beynon, 2012). Es por ello que alternativas como la fitoterapia se presenta como alternativa eficaz para el control de parásitos gastrointestinales en ovinos (Souza et al., 2008; Nery et al., 2009; Lobo et al., 2010; Oliveira et al., 2010; Krychak-Furtado et al., 2011; Puerto Abreu et al., 2014; Cunha et al., 2014). También para el tratamiento antibacteriano y antifúngico (Schuch, 2007; Cleff, 2008; Lobo et al., 2010). Otras alternativas para el control de los 
helmintos se encuentran en el uso de plantas ricas en taninos (Ramírez-Restrepo et al., 2004; 2005; Minho et al., 2010; Hoste et al., 2012), la homeopatía (Zacharias et al., 2008) y los hongos nematófagos (Mota et al., 2003; Graminha et al., 2005).

\section{h) que evite canales concentrados y monopolizados por el capital para la circulación de los productos}

Debería apoyarse en canales de comercialización que disminuyan los niveles de concentración y expropiación del trabajo generado por parte de capitales industriales y comerciales, algo que se ve favorecido en las propuestas de integración vertical de pequeños productores familiares a las cadenas de valor hegemonizadas por la industria y/o por los intermediarios. Es por ello que se busca la generación de alternativas de comercialización que fortalezcan vínculos directos ente productores y consumidores, compras del estado y propuestas asociativas de procesamiento y comercialización.

\section{Situación de la producción ovina agroecológica en la RM}

Como fue mencionado antes, las dificultades de diferenciar entre la agricultura o producción orgánica y la agroecológica, no solo tiene relevancia académica, sino también lo ha tenido en la práctica, especialmente en las definiciones de algunas políticas agropecuarias nacionales. Por eso, para analizar sus expresiones en la producción pecuaria, es importante mencionar los procesos que han vivido estas propuestas en la ganadería uruguaya.

\subsection{La ganadería orgánica en el país}

El impulso de la producción ganadera orgánica en Uruguay ocurrió en la década de 1990, a partir de algunas de las principales industrias frigoríficas, dadas las posibilidades que ofrecían las características propias de la producción ganadera uruguaya (históricamente realizada sobre pasturas naturales y con mínima utilización de insumos) para acceder a nuevos potenciales mercados internacionales de carne orgánica y ecológica (Rodríguez Gatti, 2010). La base para ello fueron grandes establecimientos pecuarios, fuertemente articulados con las principales industrias frigoríficas (de capitales extranjeros) y con su certificación realizada por empresas certificadoras internacionales. Pero existe una dificultad importante al momento de analizar la información de fuentes oficiales, especialmente del Censo General Agropecuario (CGA), debido a que allí se identifican de la misma manera (como establecimientos que certifican de su producción como orgánica) situaciones muy diferentes. Por un lado grandes productores ganaderos de base empresarial, que producen con trabajo asalariado y sin gran incorporación de nuevas propuestas tecnológicos, que están vinculados estrechamente en planes de negocios con la industria frigorífica de capitales transnacionales, cuya producción se destina principalmente a la exportación y es certificada por empresas extranjeras. Por otro pequeños agricultores familiares, generalmente con producción diversificada en base al trabajo familiar e introduciendo el manejo integrado de base ecológica, que producen principalmente con destino al mercado interno y local, cuya certificación se realiza por sistemas participativos de garantía. La muestra de 
ello es que, al analizar en el CGA de 2011 el tipo de productores que certificaron su producción como orgánica a lo largo de país, la gran mayoría se reparte entre aquellos dedicados a la ganadería bovina de carne como principal rubro (34\%) y aquellos dedicados al monocultivo forestal ( $30 \%$ del total). Éstos productores eran tan solo 511 en total, pero sumados ocupaban cerca de 994.000 hectáreas, lo que representaba el $95 \%$ del total de la superficie en manos de productores certificados como orgánicos y el $6 \%$ de la superficie agropecuaria del país para ese año.

Se evidencian entonces algunas de las fuerte contradicciones de la normativa nacional que regula la certificación, donde se utiliza el término "producción orgánica" para denominar de forma indiferenciada a la producción orgánica, la agroecológica y la biológica dentro de la misma definición. Es así que una de las pocas herramientas normativas que propone contribuir "a la conservación del ambiente y de la agricultura familiar", así como "obtener agro ecosistemas sustentables desde el punto de vista social, ecológico y económico" (Uruguay, 2008), hasta el momento principalmente regula y ofrece las condiciones a producciones fuertemente concentradas en pocos productores muy grandes $\mathrm{y}$ en algunas cadenas agroindustriales de capitales transnacionales, destinadas a la exportación.

\subsection{La Región Metropolitana}

Ya fue mencionado el aumento que experimentó la producción ovina en la RM durante los últimos 15 años. Al mismo tiempo ocurrió una importante disminución en la cantidad de productores cuyo ingreso principal dependía de la horticultura, la ganadería bovi- na de carne y la producción de carne de cerdo (MGAP, $2001 ; 2013)$. Y ese crecimiento de los ovinos en la Región sucedió principalmente en predios menores a 50 hectáreas. Para el año 2011 el 78\% de los predios con ovinos de Canelones y el $97 \%$ para Montevideo no superaban esa superficie (MGAP, 2013). Al centrarse entonces en los predios con menos de 50 hectáreas de éstos Departamentos se observa el crecimiento de los ovinos en los últimos años, especialmente intenso a partir del año 2012 (Figuras 1 y 2). Se observa que ese crecimiento ocurrió sin darse un aumento importante de la superficie total dedicada a los ovinos, por lo que en ambos Departamentos creció la dotación general (cantidad de animales por hectárea). También queda claro el perfil criador que se ha instalado en la RM, siendo que la categoría que aumentó su presencia fue la de ovejas.

Pero en cuanto a los productores de la Región que para el último Censo (año 2011) certificaban el manejo en sus predios como orgánico o agroecológico, eran muy pocos los que tenían ovinos (diecisiete), siendo apenas cuatro aquellos para los cuales la producción ovina representaba uno de sus principales ingresos (Tabla 1).

Esto se refleja también al momento de identificar expresiones organizativas de ésta propuesta. Si bien a la interna de la RAU existía interés en avanzar sobre el desarrollo del manejo agroecológico de rumiantes, por el momento las experiencias de manejo agroecológico de ovinos aparecen como incipientes y a partir de agricultores individuales. En el caso de la CNFR, como se menciona más adelante, desde hace varios años vienen avanzando en el apoyo al desarrollo de la producción ovina de la región, pero sin una propuesta tecnológica o de manejo concreta detrás, por lo que no ha habido un apoyo explícito para avanzar hacia un modelo tecnológico de base agroecológico. 

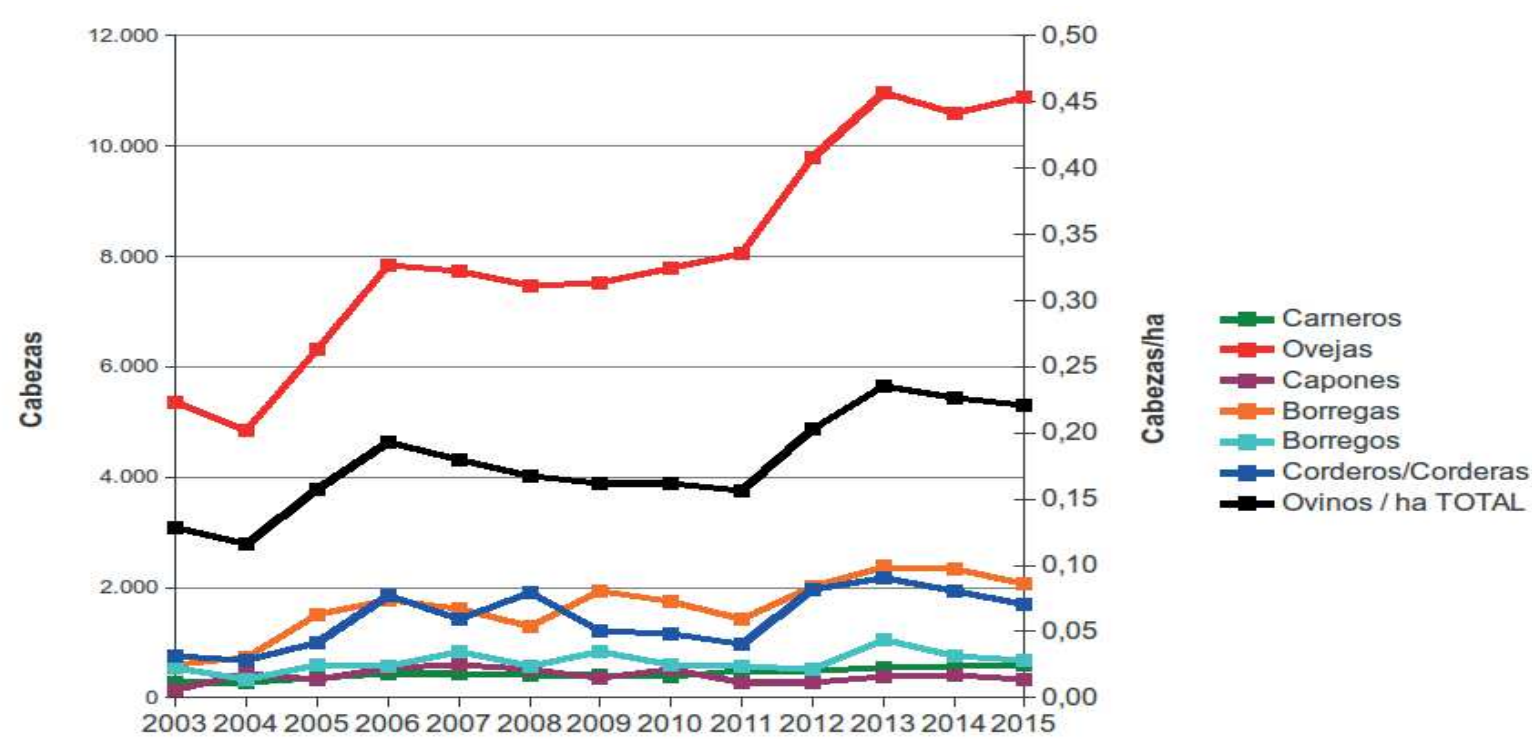

Año

FIGURA 1 - Evolución del stock ovino según su categoría, en predios menores a 50 hectáreas del Departamentos de Canelones, Uruguay. FUENTE: elaboración propia a partir de bases de datos de Declaraciones Juradas de DICOSE-MGAP entre los años 2003-2015 (MGAP, 2015).
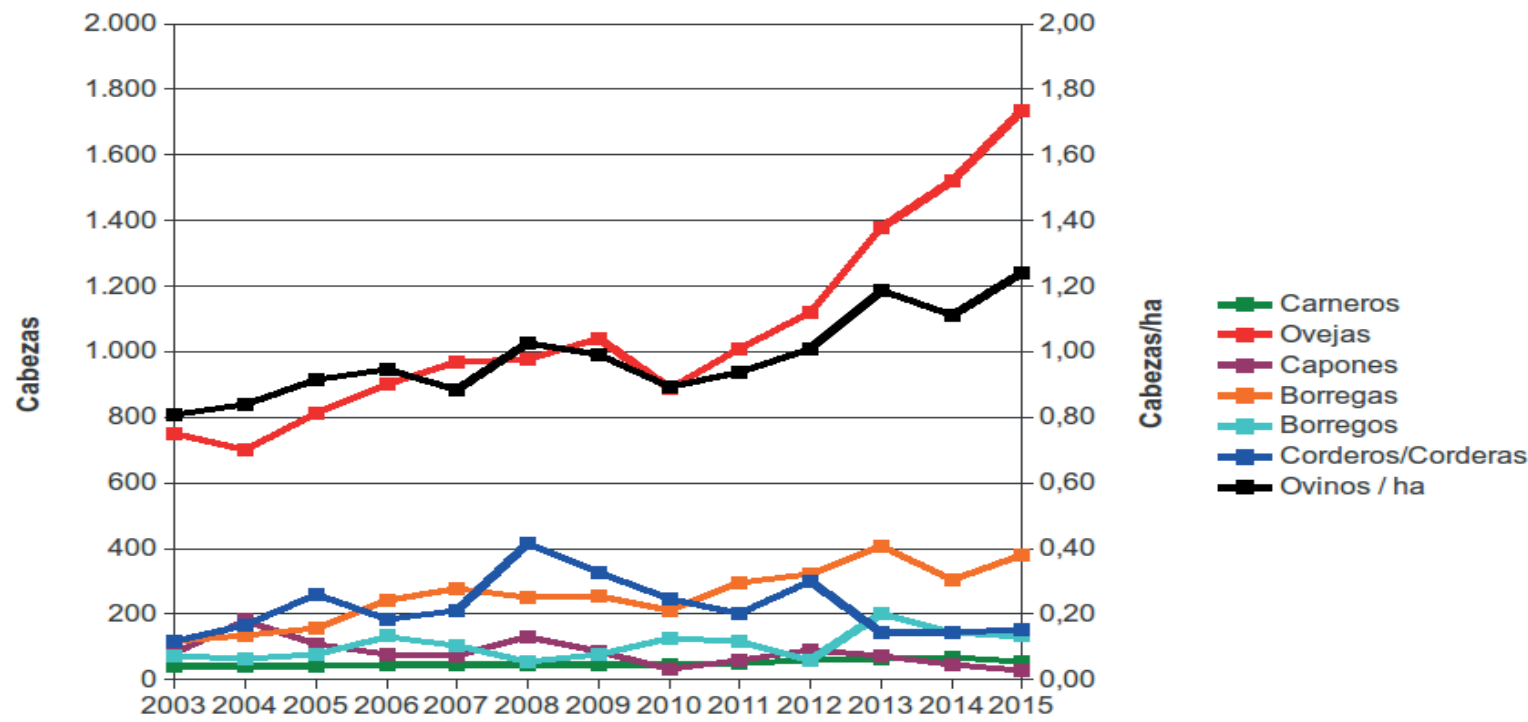

Año

FIGURA 2 - Evolución del stock ovino según su categoría, en predios menores a 50 hectáreas del Departamentos de Montevideo, Uruguay. FUENTE: elaboración propia a partir de bases de datos de Declaraciones Juradas de DICOSE-MGAP entre los años 2003-2015 (MGAP, 2015). 
TABLA 1 - Establecimientos con producción orgánica certificada e importancia de la producción ovina en el total predial, para los departamentos de Canelones y Montevideo y para el total del país en el año 2011.

\begin{tabular}{|c|c|c|c|c|c|c|c|c|c|}
\hline & \multicolumn{3}{|c|}{ Total país } & \multicolumn{3}{|c|}{ Canelones } & \multicolumn{3}{|c|}{ Montevideo } \\
\hline & $\begin{array}{l}\text { Cant. } \\
\text { prod. }\end{array}$ & $\begin{array}{l}\text { Sup. } \\
\text { prom. } \\
\text { (ha) }\end{array}$ & $\begin{array}{l}\text { Ovinos prom. } \\
\text { (cabezas) }\end{array}$ & $\begin{array}{l}\text { Cant. } \\
\text { prod. }\end{array}$ & $\begin{array}{l}\text { Sup. } \\
\text { prom. } \\
\text { (ha) }\end{array}$ & $\begin{array}{c}\text { Ovinos } \\
\text { prom. (cabe- } \\
\text { zas) }\end{array}$ & $\begin{array}{l}\text { Cant. } \\
\text { prod. }\end{array}$ & $\begin{array}{l}\text { Sup. } \\
\text { prom. } \\
\text { (ha) }\end{array}$ & $\begin{array}{c}\text { Ovinos } \\
\text { prom. (cabe- } \\
\text { zas) }\end{array}$ \\
\hline $\begin{array}{l}\text { Total producto- } \\
\text { res certificados }\end{array}$ & 807 & 1301 & 249 & 109 & 98 & 5 & 38 & 11 & 1 \\
\hline $\begin{array}{l}\text { Certificados c/ } \\
\text { ovinos }\end{array}$ & 314 & 1780 & 640 & 14 & 244 & 40 & 3 & 5 & 7 \\
\hline $\begin{array}{l}\text { Certificados c/ } \\
\text { ovinos principal } \\
\text { fuente de } \\
\text { ingresos }\end{array}$ & 43 & 1084 & 247 & 3 & 82 & 84 & 1 & 7 & 12 \\
\hline
\end{tabular}

FUENTE: elaboración propia en base a los micro datos del CGA del año 2011.

\section{Perspectivas de la POA en la Región Metropolitana}

Más allá de visualizar la situación actual y el proceso que llevó a ella, durante la investigación que sustenta éste trabajo se intentó identificar y analizar los principales factores que juegan a favor y en contra del desarrollo de la POA en la Región, los cuales se presentan a continuación.

\subsection{Factores que juegan a favor de su desarrollo}

a) Desarrollo de la producción ovina en la Región desde la agricultura familiar

Las situación de crecimiento de la producción ovina en la RM, fundamentalmente en predios de agricultores familiares, junto al desarrollo de herramientas de apoyo asociativo como lo ha sido la conformación de Fondos Rotatorios de Ovinos (Ganzábal, 2014), presentan una base donde la POA podría sustentarse de forma cada vez más firme. En este sentido CNFR viene gestionando uno de estos fondos rotatorios desde hace más de diez años, presentando un gran potencial de desarrollo de ésta producción a partir de una herramienta asociativa que viene siendo exitosa.

\section{b) Existencia de agricultores con interés en éste tipo de manejo}

Ese crecimiento de la producción ovina en la RM durante los últimos años permitió que los agricultores la visualicen como una posibilidad interesante, no solamente para integrar un nuevo ramo productivo para sus establecimientos, sino también para intentar hacerlo de forma diferente a la cría tradicional en el país. La menor experiencia en esta producción así como el interés de integrarla con las producciones hortícolas ya existentes, con el menor uso posible de insumos externos (en especial de síntesis industrial), hace que existan agricultores interesados en desarrollar una producción de base agroecológica. 
c) Potenciales mercados para estos productos y existencia de redes

En los últimos años las características de los alimentos, en referencia a la calidad y condiciones de producción vienen preocupando cada vez más a los consumidores, principalmente en la RM. En especial aquellos productos que en su forma de producción no sean prejudiciales a la salud y que no contengan residuos de antibióticos o agrotóxicos. Por eso la posibilidad de producir corderos agroecológicos u orgánicos aparece como una alternativa que hasta el momento no tiene mucha experiencia y que podría tener un potencial muy fuerte. Otro tema potencial a ser explorado es el de la lana y las posibilidades de los propios grupos de agricultores para realizar su procesamiento y venta artesanal. Lo mismo ocurre con la leche ovina, dadas las características lecheras de algunas de las razas que están creciendo en la Región, aunque en este sentido ya existieron algunos intentos para su desarrollo y no surgen con tanta claridad condiciones para su implementación en pequeños establecimientos familiares.

\section{d) Existencia de experiencias de} producciones vegetales de base agroecológica en la Región

La existencia desde hace años de experiencias de producción agroecológica en la RM es una base importante para pensar la integración de la producción ovina dentro de este tipo de manejo. Aunque esas experiencias estén concentradas fundamentalmente en la producción hortícola, existen intentos incipientes de integración con la producción animal
(Bacigalupe \& Salvo, 2007) y de cualquier forma son un acúmulo importante para pensar la posibilidad de integrar los ovinos a esos sistemas. Si bien aún no hay muchas experiencias en el manejo de ovinos, muchos de los agricultores de la Región tienen un potencial importante desde su experiencia y conocimiento en el manejo ecológico de sus agroecosistemas.

\section{e) Necesidad y demanda de alternativas tecnológicas para el control parasitario}

Los nematodos gastrointestinales son el principal problema o enfermedad que afecta la producción ovina en el país y es una de las afecciones que genera mayores pérdidas productivas en los países de regiones tropicales y subtropicales (FAO, 2003). En el Plan Nacional de Investigación en Salud Animal (PLANISA) se menciona como principal causa de ello la resistencia cada vez mayor de los parásitos a los antihelmínticos de síntesis industrial (Gil et al., 2009), algo compartido con los países de la región (Argentina, Brasil y Paraguay) (Torres-Acosta et al., 2012). El último estudio importante realizado en el país sobre el tema es de la década de 1990 y se identificó que más del $80 \%$ de los 252 establecimientos analizados presentaba algún tipo de resistencia a los antiparasitarios (Nari, 1996) situación que se estima se ha agravado desde aquel momento (Mederos \& Banchero, 2013).

Esta situación, que en principio se presenta como una dificultad para la producción ovina en general, puede ser tomada como una potencialidad en la búsqueda de implementar manejos de base agroecológica, donde el manejo preventivo y de control parasitario de forma integrada podría oficiar 
como un estímulo rumbo a esa búsqueda tanto por parte de los agricultores como de los técnicos e instituciones de investigación.

\subsection{Factores en contra y limitantes para su desarrollo}

\section{a) Casi inexistencia de experiencias de POA} funcionando en el país

Son mínimas las experiencias concretas funcionando hasta el momento de manejo agroecológico de ovinos, que puedan servir como ejemplo o referencia de implementación para otros agricultores y como bases de investigación. Entre algunas de las posibles causas de esta situación ya se mencionó la situación general de la producción ganadera orgánica, estimulada sin grandes propuestas de cambio en el manejo histórico y en manos de grandes productores, con certificación por parte de empresas internacionales, cuyos costos son inaccesibles para pequeños agricultores. Aunque existen interesantes experiencias de producción orgánica de leche en la región suroeste del país, sus condiciones son bastante diferentes a las de la producción ovina de la RM, dado que se realiza principalmente en establecimientos especializados en esta producción y situados dentro de la principal cuenca lechera del país, siendo sus principales propuestas la sustitución de productos de síntesis industrial por estrategias de manejo y el tratamiento sanitario en base a homeopatía (Martin \& Riet Correa, 2008). Otro aspecto que dificulta es la fuerte presencia y peso de capitales transnacionales en las distintas fases de la cadena ovina (insumos, comercialización, industria), con intereses contrapuestos a la propuesta.

\section{b) No siempre se visualiza la necesidad un manejo diferente al actual}

La propia característica histórica de la ganadería en Uruguay, basada en pasturas naturales y uso mínimo de insumos externos, hace que sea más difícil visualizar los por qué de otro modelo técnico y de manejo. Esto se refleja también en la RM, a pesar que allí la tradición ganadera no es tan fuerte como en otras regiones, pero es un acúmulo cultural muy presente en todo el país. Ello se vincula a otro aspecto particular de la producción animal, que es la menor percepción que generalmente los trabajadores tienen en relación a los riesgos que implica el uso y abuso de medicamentos veterinarios de síntesis industrial. Un trabajo realizado por Da Silva et al. (2012) a partir de la percepción de los trabajadores de la pecuaria lechera de una región de São Paulo, Brasil, con relación al manejo de insecticidas de síntesis industrial, muestra cómo la falta de información y apoyo técnico conduce a que los trabajadores no vinculen estos agrotóxicos y su uso con o riesgos en sus trabajos, visualizándolos inclusive como remedios y no como venenos. Inclusive, ante los mismos principios activos pero usados en la producción vegetal, en muchos casos la percepción es totalmente diferente, allí si identificándolos como prejudiciales para la salud y para el ambiente. También mencionan que los trabajadores muchas veces no consiguen vincular claramente el lugar donde se aplica el producto (los animales) con el producto que luego se obtiene de ellos y se consume (leche, carne, lana), lo que favorece a la invisibilidad de su presencia y con eso muchas veces a la negligencia en las formas de sus usos y el no respeto a los tiempos de espera entre la aplicación del agrotóxico y el consumo. 
c) Falta de información y formación para agricultores y técnicos

La falta de alternativas de formación y capacitación es una de las debilidades de la producción ovina en general para la RM, lo que se profundiza para el caso de proponerse un manejo de base agroecológica. Es mucho menor la información y posibilidades de formación con la que cuentan agricultores y técnicos sobre esta alternativa de manejo, muy especialmente para las producciones animales. En particular se encuentran lagunas importantes en aspectos de manejo sanitario y alimentación.

\section{d) Falta de investigación hacia un manejo de base agroecológica}

Otro de los elementos que surgen como claves para el desarrollo de esta propuesta es la investigación enfocada a estos agroecosistemas. En ese sentido la contribución desde las principales instituciones vinculadas a la investigación agropecuaria es relativamente muy pequeña, generalmente con contribuciones puntuales en algunos aspectos específicos y poco coordinados. En particular sobre la integración de la producción ovina al agroecosistema es uno de los elementos donde parece ser más difícil encontrar contribuciones, aunque sean puntuales. Existen diversos esfuerzos, principalmente desde la Facultad de Agronomía, en el análisis global de agroecosistemas que integran horticultura y ganadería, pero específicamente considerando ganado bovino y con poco énfasis en los procesos biológicos vinculados a esa integración de la producción animal con la vegetal, sino más bien desde el punto de vista económico y de la organización del trabajo (Aguerre, 2011; Dogliotti et al., 2012).

El aspecto sobre el que sí se viene avanzando más hasta el momento e implementando distintas líneas de investigación, es en la búsqueda de tratamientos sanitarios alternativos, principalmente para el control de nematodos gastrointestinales. Hay dos grandes líneas principales en ese sentido, aunque sean incipientes o estén en etapa experimental inicial. Una vinculada a la selección genética de ovinos resistentes a los parásitos gastrointestinales (Ciappesoni et al., 2009; Goldberg, 2011; Goldberg et al., 2012). La otra pasa por el uso de forrajes bioactivos (aquellos con compuestos secundarios que ejercen algún efecto de control sobre éstos parásitos, como por ejemplo Lotus pedunculatus y L. corniculatus) o por la administración de taninos condensados desde otras fuentes (por ejemplo extracto de Quebracho -Shinopsis spp.-) para el control parasitario (Mederos \& Banchero, 2013). Por el momento ambas líneas de investigación se desarrollan de forma bastante aislada y sin mayores propuestas de cambios generales en el sistema de manejo rumbo a sistemas de base agroecológica o que por lo menos se aproxime a eso. En general se fundamentan en la sustitución de productos de síntesis industrial por otros de base natural y no tanto en cambios en el manejo que busque favorecer los procesos naturales dentro de los agroecosistemas, o que haga foco en el manejo preventivo. Inclusive, en el caso de la selección genética se está trabajando a partir de sociedades de grandes criadores de las principales razas del país, por lo que inicialmente será difícil que genere impactos directos en los sistemas de la RM que son objeto de éste trabajo. 
e) Falta de apoyo o planes específicos a partir de las políticas públicas

Hasta el momento son mínimas las políticas específicas y de importancia que apoyen o estimulen la producción agroecológica, más allá de las reglamentaciones que ya fueran mencionadas sobre la producción orgánica y la presencia del componente ambiental en varios proyectos y programas del MGAP. En los últimos años se generaron llamados a proyectos para unidades productivas (Producción Familiar Integral y Sustentable) y para organizaciones (Promoción y Desarrollo de Tecnologías Apropiadas para la Producción Familiar) con foco en la implementación de tecnologías específicas para la agricultura familiar (MGAP, 2014a; 2014b). En ambos casos se trata de proyectos financiados a través de préstamos del Banco Interamericano de Desarrollo (BID) y en su contenido colocan un enfoque integral, procurando incorporar los aspectos productivos, ambientales, económicos y sociales. Pero en estos casos, el hecho de basarse en proyectos a término y generalmente con objetivos bastante parciales, sin un Plan que trace grandes líneas estratégicas sobre el tema, hace que sean pocas sus posibilidades de servir realmente como herramienta de desarrollo, inclusive dependiendo en gran medida de las capacidades de los agricultores, técnicos y organizaciones concretas que las implementen en cada Región.

Esta situación tampoco escapa a la realidad de países vecinos, inclusive en Brasil donde la agroecología tuvo un importante desarrollo desde los movimientos e organizaciones sociales y también desde el Estado. A pesar de ello, Caporal \& Petersen (2012) colocan que las políticas públicas en Brasil también tienen la dificultad de presentarse de forma puntual desde algunas iniciativas del Estado, sin una intencionalidad de proponerse como un modelo de desarrollo. La propuesta neodesarrollista sigue siendo la que se impone como guía general en los diferentes ámbitos de la vida en el campo, la producción agropecuaria y la economía en general.

\section{f) No hay una priorización de ésta línea de trabajo desde las principales organizaciones de la agricultura familiar}

Otras de las dificultades para pensar el desarrollo de este tipo de propuesta está en que las principales organizaciones que nuclean a los agricultores familiares (en particular la CNFR) no priorizan ni colocan la cuestión de los modelos productivos y tecnológicos como una problemática central. El centro de sus principales luchas y demandas han estado en la búsqueda de políticas públicas diferenciadas para la agricultura familiar, con un claro posicionamiento en contra del modelo del agronegocio, pero sin poder avanzar en propuestas o demandas de modelos tecnológicos alternativos (CNFR, 2009). Aunque mencionen la necesidad de avanzar en la investigación y desarrollo de tecnologías específicas para la agricultura familiar, no surge una propuesta que rompa el modelo tecnológico, mucho menos se menciona la agroecología o producción de base ecológica. Esta situación contrasta con la realidad de la mayoría de las organizaciones que vinculan a los agricultores familiares y campesinos en el resto da América Latina y el mundo, donde la agroecología se coloca como herramienta central dentro de sus propuestas de desarrollo, de soberanía alimentaria y de lucha frente al avance del capital en el campo (La Vía Campesina, 2013). 


\section{Consideraciones finales y desafios por delante}

Tal como fue presentado en este trabajo, la POA se encuentra en una etapa incipiente, pero comienza a mostrarse como una interesante alternativa de resistencia y propuesta para los agricultores familiares de la RM y sus organizaciones. Sin embargo, para que pueda desarrollarse como tal, se deberá avanzar especialmente en superar algunos de los principales factores que lo dificultan o limitan. Especialmente hay tres componente sobre los que parecería necesario y prioritario avanzar: a) generación de conocimiento sobre éste tipo de manejo, adaptado a las condiciones de ésta Región; b) políticas públicas específicas y apoyos estatales que incentiven ésta propuesta; c) mayor apropiación por parte de las organizaciones de agricultores familiares.

Respecto a la generación de conocimiento e investigación local, se presentan al menos dos ejes sobre los que sería fundamental profundizar. En primer lugar avanzar sobre posibles alternativas para el manejo sanitario, principalmente la prevención y control de los parásitos gastrointestinales, dentro de sistemas agroecológicos. En ese sentido, será necesario profundizar en generar estrategias de Control Integrado de Parásitos (CIP), adaptadas a las condiciones de la RM y que incluyan el manejo del pastoreo (descanso de pasturas, pastoreo alternado entre distintas categorías o especies, pastoreo rotativo, uso de áreas de rastrojo, silvopastoreo), el manejo animal (buena dieta en cantidad y calidad principalmente en el aporte proteico, alimentos con mayor grado de taninos, selección de animales resistentes) y el desarrollo de nuevas estrategias de control y prevención (uso de hongos nematófagos, fitoterapia y otras terapias alternativas) (FAO, 2003; Molento et al., 2013). Otro eje sobre el cuál avanzar sería en la investigación de alternativas de integración de los ovinos en agroecosistemas complejos de ésta Región, en particular la evaluación e implementación de herramientas como el Pastoreo Racional Voisin (PRV), que se presenta como un sistema de manejo de agroecológico de los agroecosistemas pastoriles (Pinheiro Machado, 2011). Hasta el momento la investigación sobre el PRV, analizando sus posibilidades de implementación o adaptación a las condiciones locales casi no está presente en las agendas nacionales de investigación. Mientras tanto en los países vecinos, especialmente en los estados del Sur de Brasil, es cada vez más importante la implementación de proyectos de PRV y la investigación sobre el tema (Lenzi, 2003; Graeff Erpen, 2004; Kerber, 2005; Meira Cordeiro, 2008; Machado \& Balem, 2012), inclusive con experiencias en producción ovina (Mayer \& Burg, 2011; Heneriche, 2014).

En cuanto al apoyo a éste tipo de propuestas desde la institucionalidad pública, los aportes no solo deberían estar en el componente productivo, sino también en las etapas de faena, procesamiento y comercialización. Generalmente es en estas últimas etapas donde se da la mayor extracción del excedente producido por los agricultores, por parte de intermediarios, capitales comerciales y/o industriales. Actualmente existen propuestas interesantes, como lo es la Planta de Faena Móvil que aún está en etapa de validación por el Instituto Nacional de Carnes (INAC) y pretende servir como local de faena para pequeños productores de la RM (INAC, 2015a, 2015b). Esta planta permitiría a grupos de agricultores cerrar el ciclo de producción y faena 
dentro de la Región y así poder vender directamente a los consumidores un producto con cuidados tanto en su forma de producción como en su proceso de faena. A esto podría sumarse la posibilidad de generar marcas o etiquetas comunes entre grupos de productores agroecológicos de ovinos, para asociarse y comercializar colectivamente. También avanzar hacia el sistema de compras públicas por parte de instituciones del estado, aprovechando la reciente legislación que busca aportar en ese sentido (Uruguay, 2014). En cuanto a la comercialización, los puntos de venta ya existentes gestionados por la RAU se presentan como posibilidades a explorar también para los productos ovinos.

El tercer componente sobre el cual avanzar refiere a la necesidad de ampliar la apropiación de éste tipo de propuestas por parte de las organizaciones sociales que nuclean a los agricultores familiares de la Región, así como profundizar vínculos entre éstas organizaciones y aquellas más enfocadas al desarrollo de la agroecología. Tal como fuera mencionado antes, a partir de los que propone Oyhantçabal (2013) respecto a la existencia de disputas territoriales en Uruguay entre la agricultura familiar y el capital, las posibilidades de desarrollo de la agricultura familiar sin estar subsumida y totalmente dependiente a este último, requiere también avanzar hacia modelos tecnológicos que resistan y combatan esa dependencia. En la actualidad está comenzando a funcionar una línea de trabajo conjunta entre $\mathrm{CN}$ FR y la RAU, que también involucra instituciones de investigación y enseñanza, para avanzar en el desarrollo de la producción ovina agroecológica en la RM, pero fundamentalmente desde la coordinación entre organizaciones de base y con presencia territorial común.
De la fortaleza que generen las organizaciones sociales en torno al tema y en su vínculo con las instituciones públicas de investigación y desarrollo, dependerá gran parte de la posibilidades de que la POA crezca y se posicione como una alternativa viable dentro de las estrategias de resistencia y propuesta de los agricultores familiares en la RM.

\section{Referencias}

Acosta, M. L.; Arretche, A. Comercialización internacional de carne ovina: una nueva perspectiva. Montevideo, Trabalho de Conclução de Curso (Contador Público) - UDELAR, 2010.

Aguerre, M. V. Exploración de alternativas para el desarrollo sostenible de sistemas de producción hortícola-ganaderos en predios familiares de Canelones-Uruguay. Montevideo, Dissertação (Magister en Ciencias Agrarias) - UDELAR, 2011.

Bacigalupe, G. F.; Salvo, G. Selección de indicadores para la evaluación de la sustentabilidad en sistemas de producción orgánica en los departamentos de Montevideo y Canelones. Montevideo, Trabalho de Conclução de Curso (Ingeniero Agrónomo) - UDELAR, 2007.

Barrán, J. P. Apogeo y crisis del Uruguay pastoril y caudillesco. Historia Uruguaya, Tomo 4. Montevideo: Banda Oriental, 2007.

Beynon, S. A. Potential environmental consequences of administration of anthelmintics to sheep. Veterinary Parasitology, 189, 113-124, 2012. doi: 10.1016/j.vetpar.2012.03.040

Canales, M.; Peinado, A. Grupos de discusión. In: Delgado, J. M.; Gutiérrez Ferández, J. (Coord.). Métodos y técnicas cualitativas de investigación en ciencias sociales. España: Síntesis, p. 288-316, 1995.

Caporal, F. R.; Petersen, P. Agroecologia e políticas públicas na América Latina: o caso do Brasil. Agroecologia, 6, 63-74, 2012. Disponível em: http://revistas.um.es/agroecologia/ article/view/160681/ 
Carvalho, H. M. de. Agricultura familiar y el campesinado en América Latina. Montevideo: Extensión Libros, 2013.

Ciappesoni, G.; Mederos, A.; De Barbieri, I.; Rodríguez, A.; Kelly, L.; Nicolini, P.; Goldberg, V.; Montossi, F. Resistencia genética a parásitos gastrointestinales en ovinos: el enfoque del INIA. Agrociencia, 13(3), 83, 2009. Disponível em: http://www.fagro.edu.uy/agrociencia/index.php/directorio/ article/view/239

Cleff, M. B. Avaliação da atividade antifúngica do óleo esencial de Origanum vulgare L. frente a fungos de importancia em veterinaria com énfase em Cándidad spp. Porto Alegre, Tese (Doctor em Ciencias Veterinárias) - UFRGS, 2008.

CNFR - Comisión Nacional De Fomento Rural. Propuesta de Políticas Públicas Diferenciadas para el Desarrollo de la Agricultura Familiar, 2009. Disponível em: <http://www. cnfr.org.uy/uploads/files/propuesta_politicas_diferenciadas_para_la_AF.pdf $>$. Acesso em: fev. 2015.

Cunha, M. P. V.; Alves Neto, A. F.; Suffredini, I. B.; Abel, L. J. C. Avaliação da atividade anti-helmíntica de extratos brutos de plantas da Floresta Amazônica e Mata Atlântica brasileira sobre Haemonchus contortus. Arquivo Brasileiro de Medicina Veterinária e Zootecnia, 66(2), 374-380, 2014. doi: 10.1590/1678-41626313

Da Silva, T. P. P.; Moreira, J. C.; Peres, F. Serão os carrapaticidas agrotóxicos? Implicações na saúde e na percepção de riscos de trabalhadores da pecuária leiteira. Ciência \& Saúde Coletiva, 17(2), 311-325, 2012. doi: 10.1590/S141381232012000200006

Devendra, C.; Thomas, D. Crop-animal interactions in mixed farming systems in Asia. Agricultural Systems, 71, 27-40, 2002. doi: 10.1016/S0308-521X(01)00034-8

Díaz, I. Modelación de los aportes de nitrógeno y fósforo en cuencas hidrográficas del departamento de Canelones (Uruguay). Montevideo, Dissertação (Magister en Ciencias Ambientales) - UDELAR, 2013.

Dogliotti, S.; Abedala, C.; Aguerre, V.; Albin, A.; Alliaume, F.; Álvarez, J.; Bacigalupe, G.F.; Barreto, M.; Chiappe, M.; Corral, J.; Dieste, J.P.; García de Souza, M.C.; Guerra, S.; Leoni, C.; Malán, I.; Mancassola, V.; Pedemonte, A.; Peluffo, S.; Pombo, C.; Salvo, G.; Scarlato, M. Desarrollo sostenible de sistemas de producción hortícolas y hortícola-ganaderos familiares: Una experiencia de co-innovación. Montevideo: INIA, 2012.

FAO - Organización de las Naciones Unidas para la Agricultura y la Alimentación. Resistencia a los antiparasitarios: Estado actual con énfasis en América Latina, 2003. Disponível em: <http://www.fao.org/docrep/006/y4813s/ y4813s00.htm\#Contents>. Acesso em: fev. 2015.

Fernandes, B. M. Territorio, teoría y política. In: Calderón Aragón, G.; León Hernández, E. (Coords.). Descubriendo la Espacialidad Social desde América Latina. Reflexiones desde la geografía sobre el campo, la ciudad y el medio ambiente, 2012. Disponível em: $<$ https://horizontescomunitarios.files.wordpress.com/2016/10/mancano-fernandez-territorios-teoria-y-politica.pdf $>$. Acesso em: nov. 2015.

Figueiredo, C. C.; Ramos, M. L. G.; McManus, C. M; Menezes, A. M. Mineralização de esterco de ovinos e sua influência na produção de alface. Horticultura Brasileira, 30(1), 175-179, 2012. doi: 10.1590/S0102-05362012000100029

Finch, H. La economía política del Uruguay contemporáneo: 1870-2000. Montevideo: Banda Oriental, 2005.

Foladori, G. Proletarios y campesinos. 1. ed. Xalapa: Universidad Veracruzana, 1986.

Ganzábal, A.; Montossi, F.; Banchero, G.; San Julián, R.; De Barbieri, I. Producción ovina intensiva: La experiencia de INIA. In: Perrachón, R.; Peinado, G.; Ganzábal, A.; Montossi, F.; Banchero, G.; San Julián, R.; De Barbieri, I. Sistemas ovinos intensivos del litoral sur del Uruguay: Enfoques de la investigación, transferencia de tecnología y extensión. Montevideo: INIA, p. 49-79, 2001.

Ganzábal, A. Experiencias en planes ovinos en Uruguay como herramienta de desarrollo de la ovinocultura en pequeña escala. In: Ganzábal, A. (Ed.). Guía práctica de producción ovina en pequeña escala en Iberoamérica. CYTED, p. 186-190, 2014.

García de Souza, M.; Alliaume, F.; Mancassola, V.; Dogliotti, S. Carbono orgánico y propiedades físicas del suelo en predios hortícolas del sur de Uruguay. Agrociencia, 15(1), 70-81, 2011. Disponível em: <http://www.fagro.edu.uy/ agrociencia/index.php/directorio/article/view/97> 
García Ferreira, R.; Tommasino, H.; Marzaroli, J.; Gutiérrez, R. Impacto de estrategias colectivas en la sustentabilidad de sistemas familiares lecheros en Uruguay. Pastos y Forrajes, 34(1), 109-120, 2011. Disponível em: <https://payfo. ihatuey.cu/index.php?journal=pasto $\&$ page $=$ article $\& o p=-$ view\&path $\% 5 \mathrm{~B} \% 5 \mathrm{D}=586>$

García Trujillo, R.; Rebollo Vergara, X. Producción ecológica de ovinos, [s. d.]. Disponível em: <http://www. juntadeandalucia.es/agriculturaypesca/portal/export/sites/ default/comun/galerias/galeriaDescargas/cap/produccion-ecologica/folletoovino.pdf>. Acesso em: dez. 2014.

Gil, A.; Nari, A.; Hirigoyen, D. Propuesta de líneas de investigación y acciones para el PLANISA, 2009. Disponível em: $<$ http://www.fvet.edu.uy/planisa/files/Trabajo_final_090904.pdf>. Acesso em: jan. 2015.

Goldberg, V. Estimación de parámetros genéticos de la resistencia a nematodos en el periodo del periparto y pos-destete en ovinos Merino del Uruguay. Valencia, Tesina (Máster en Mejora Genética Animal y Biotecnología de la Reproducción) - UPV, 2011.

Goldberg, V.; Ciappesoni, C. G.; Aguilar, I. Genetic parameters for nematode resistance in periparturient ewes and post-weaning lambs in Uruguayan Merino sheep. Livestock Science, 147(1-3), 181-187, 2012. doi: 10.1016/j. livsci.2012.05.003

Gómez Perazzoli, A.; Galeano, P. Manual operativo y Guía de Formación: Programa de Certificación Participativa Red de Agroecología, 2006. Disponível em: $<$ http://redagroecologia.uy/wp-content/uploads/2014/12/manual-operativo. pdf>. Acesso em: jan. 2015.

Gonzalez Idiarte, H. Campaña de uso y manejo responsable y sostenible del suelo. In: Ministerio de Ganadería Agricultura y Pesca. Oficina de Programación y Política Agropecuária. Anuario 2008 OPYPA, 2008. Disponível em: <http:/www.mgap.gub.uy/unidad-ejecutora/oficina-de-programacion-y-politicas-agropecuarias/publicaciones/ anuarios-opypa/2008>. Acesso em: mar. 2015.

Goyenola, G.; Acevedo, S.; Machado, I; Mazzeo, N. Diagnóstico del Estado Ambiental de los Sistemas Acuáticos Superficiales del Departamento de Canelones. Volumen I: Ríos y Arroyos, 2011. Disponível em: $<$ https://www.researchga-
te.net/publication/52010743_Diagnostico_del_Estado_Ambiental_de_los_Sistemas_Acuaticos_Superficiales_del_Departamento_de_Canelones_Volumen_I_Rios_y_Arroyos $>$. Acesso em: mar. 2017.

Goyenola, G.; Acevedo, S.; Machado, I; Mazzeo, N. Diagnóstico del Estado Ambiental de los Sistemas Acuáticos Superficiales del Departamento de Canelones. Volumen III: Laguna del Cisne, 2013. Disponível em: $<$ https://www. researchgate.net/publication/52010753_Diagnostico_del_ Estado_Ambiental_de_los_Sistemas_Acuaticos_Superficiales_del_Departamento_de_Canelones_Volumen_III_Laguna_del_Cisne>. Acesso em: mar. $201 \overline{7}$.

Graeff Erpen, J. A construção de um sistema agroecológico para a bovinocultura: O PRV e a fazenda Quero-Quero. Florianópolis, Dissertação (Mestre em Agroecossistemas) - UFSC, 2004.

Graminha, E. B. N.; Monteiro, A. C.; Silva, H. C. da; Oliveira, G. P.; Costa, A. J. da. Controle de nematóides parasitos gastrintestinais por Arthrobotrys musiformis em ovinos naturalmente infestados mantidos em pastagens. Pesquisa Agropecuária Brasileira, 40(9), 927-933, 2005. doi: 10.1590/S0100-204X2005000900013

Grossi Rodrigues, M. A. Politização da Questão Ambiental no MST: a agroecologia como estratégia produtiva e política. Rio de Janeiro, Tese (Doutor em Serviço Social) - UFRJ, 2014.

Harvey, D. El "nuevo" imperialismo: acumulación por desposesión, 2005. Disponível em: $<$ http://biblioteca.clacso. org.ar/clacso/se/20130702120830/harvey.pdf > . Acesso em: dez. 2014.

Heneriche, M. L. Características estruturais em pastos de aveia e azevém submetidos a diferentes métodos de rebaixamento sob Pastoreio Racional Voisin. Florianópolis, Dissertação (Mestre em Agroecossistemas) - UFSC, 2014.

Hoste, H.; Martinez-Ortiz-De-Montellano, C.; Manolaraki, F.; Brunet, S.; Ojeda-Robertos, N.; Fourquaux, I.; Torres-Acosta, J. F. J.; Sandoval-Castro, C. A. Direct and indirect effects of bioactive tannin-rich tropical and temperate legumes against nematode infections. Veterinary Parasitology, 186, 18-27, 2012. doi: 10.1016/j.vetpar.2011.11.042

INAC - Instituto Nacional de Carnes. 30 años de informa- 
ción 1977-2006, 2006. Disponível em: <https://www.inac. gub.uy/innovaportal/file/1061/1/30_de_info.pdf >. Acesso em: oct. 2015.

INAC - Instituto Nacional de Carnes. Prototipo faena móvil, 2015a. Disponível em: <http://www.inac.gub.uy/ innovaportal/v/8324/1/innova.net/prototipo_faena_movil $>$. Acesso em: fev. 2015.

INAC - Instituto Nacional de Carnes. Expo Prado 2014, 2015b. Disponível em: <http://www.inac.gub.uy/innovaportal/v/9643/1/innova.net/expo_prado_2014>. Acesso em: fev. 2015.

INAC - Instituto Nacional de Carnes. Anuario estadistico 2016, 2016. Disponível em: <https://www.inac.gub.uy/ innovaportal/file/14228/1/anuario-estadistico-2016_web-hojas-apaisadas.pdf>. Acesso em: mar. 2017.

Kerber, R. L. Avaliação da implantação de um sistema de Pastoreio Racional Voisin no colégio agrícola de camboriú. Florianópolis, Dissertação (Mestre em Agroecossistemas) - UFSC, 2005.

Kremer, R. Corderos pesados en Uruguay: evolución e impacto en la producción de carne ovina. Agrociencia, 14(3), 69-71, 2010. Disponível em: http://www.fagro.edu. uy/agrociencia/index.php/directorio/article/view/403

Krychak-Furtado, S.; Silva, A. L. P., Miguel, O. G.; Dias, J. de F. G.; Miguel, M. D., Costa, S. S.; Negrelle, R. R. B. Effectiveness of Asteraceae extracts on Trichostrongylidae eggs development in sheep. Revista Brasileira de Parasitologia Veterinária, 20(3), 215-218, 2011. doi: 10.1590/ S1984-29612011000300007

La Vía Campesina. De Maputo a Yakarta: 5 anos de agroecología em La Vía Campesina, 2013. Disponível em: <http:// www.agroecologia.org.br/files/importedmedia/de-maputo-a-yakarta.pdf>. Acesso em: fev. 2015.

Lenzi, A. Desempenho animal e produção de forragem em dois sistemas de uso da pastagem: Pastejo Contínuo \& Pastoreio Racional Voisin. Florianópolis, Dissertação (Mestre em Agroecossistemas) - UFSC, 2003.

Lobo, K. M. S.; Athayde, A. C. R; Silva, A. M. A; Rodrigues, F. F. G; Lôbo, I. S.; Bezerra, D. A. C.; Costa, J. G. M. Avaliação da atividade antibacteriana e prospecção fitoquímica de Solanum paniculatum Lam. e Operculina hamiltonii (G. Don) D. F. Austin \& Staples, do semiárido paraibano. Revista Brasileira de Plantas Medicinais, 12(2), 227-233, 2010. doi: 10.1590/S1516-05722010000200016

Machado, R. L.; Balem, T. A. Transição agroecológica de sistemas de produção de leite: uso do Pastoreio Racional Voisin (PRV) em Santa Maria/RS/Brasil. Agroecologia e Desenvolvimento Rural Sustentável, 5(3), 17-27, 2012. Disponível em: http://www.emater.tche.br/site/sistemas/ administracao/tmp/1172444756.pdf>

Martin, F.; Riet Correa, J. Caracterizacion de la produccion organica de leche en el Uruguay: aspectos normativos y visión de sus actores. Montevideo, Trabalho de Conclução de Curso (Ingeniero Agrónomo) - UDELAR, 2008.

Marx, K. El Capital: Libro primero. Buenos Aires: Siglo Veintiuno Editores, 1. ed., 2012.

Mayer, P. H.; Burg, I. C. Manejo agroecológico de ovinos em Pastoreio Racional Voisin: uma atividade sustentável para a pequena propriedade. Cadernos de Agroecologia, 6(1), 2011. Disponível em: http://www.aba-agroecologia. org.br/revistas/index.php/cad

Mederos, A.; Banchero, G. Parasitosis gastrointestinales de ovinos y bovinos: situación actual y avances de la investigación. Revista INIA, 34, 10-15, 2013. Disponível em: http://www.ainfo.inia.uy/digital/bitstream/item/7054/1/ revista-INIA-34-p.-10-15.pdf

Meira Cordeiro, F. L. Efeito do Pastoreio Racional Voisin na pastagem, no pastoreio e na compactação do solo. Florianópolis, Dissertação (Mestre em Agroecossistemas) - UFSC, 2008.

MGAP - Ministerio de Ganadería, Agricultura y Pesca. Censo General Agropecuario 1980. Montevideo: MGAP, 1983.

MGAP - Ministerio de Ganadería, Agricultura y Pesca. Censo General Agropecuario 2000, 2001. Disponível em: $<$ http://www2.mgap.gub.uy/DieaAnterior/CENSOVOL2/ indice.htm>. Acesso em: mar. 2015.

MGAP - Ministerio de Ganadería, Agricultura y Pesca. Anuario Estadístico Agropecuario 2005, 2005. Disponível em: <http://www.mgap.gub.uy/unidad-ejecutora/oficina-de-programacion-y-politicas-agropecuarias/publicaciones/ 
anuarios-diea/anuario-2005>. Acesso em: mar. 2015.

MGAP - Ministerio de Ganadería, Agricultura y Pesca. Anuario Estadístico Agropecuario 2010, 2010. Disponível em: $<$ www.mgap.gub.uy/unidad-ejecutora/oficina-de-programacion-y-politicas-agropecuarias/publicaciones/anuarios-diea/ anuario-2010>. Acesso em: nov. 2015.

MGAP - Ministerio de Ganadería, Agricultura y Pesca. Anuario Estadístico Agropecuario 2015, 2015. Disponível em: $<$ www.mgap.gub.uy/unidad-ejecutora/oficina-de-programacion-y-politicas-agropecuarias/publicaciones/anuarios-diea/ anuario-2015>. Acesso em: nov. 2015.

MGAP - Ministerio de Ganadería, Agricultura y Pesca. Censo General Agropecuario 2011, 2013. Disponível em: $<$ http://www.mgap.gub.uy/sites/default/files/multimedia/ censo2011.pdf $>$. Acesso em: mar. 2015.

MGAP - Ministerio de Ganadería, Agricultura y Pesca. Convocatoria Pública a presentar propuestas de +Tecnologías para la producción familiar: Promoción y Desarrollo de Tecnologías Apropiadas para la Producción Familiar, 2014a. Disponível em: <http://www.mgap.gub.uy/>. Acesso em: dez. 2014.

MGAP - Ministerio de Ganadería, Agricultura y Pesca. Producción familiar integral y sustentable: Bases, 2014b. Disponível em: <http://www.mgap.gub.uy/>. Acesso em: dez. 2014.

MGAP - Ministerio de Ganadería, Agricultura y Pesca. Declaración jurada ante DICOSE. < <ttp://www.mgap.gub.uy/ unidad-organizativa/direccion-general-de-servicios-ganaderos/sanidad-animal/dicose/declaracion-jurada-ante-dicose> . Acesso em: dez. 2015.

Minho, A. P.; Filippsen, L. F.; Amarante, A. F. T. do; Abdalla, A. L. Eficácia dos taninos condensados presentes no extrato de acácia no controle de Trichostrongylus colubriformis em ovinos. Ciência Rural, 40(6), 1360-1365, 2010. doi: 10.1590/S0103-84782010005000088

Molento, M. B.; Veríssimo, C. J.; Amarante, A. T.; Wyk, J. A. Van; Chagas, A. C. de S.; Araújo, J. V. de; Borges, F. A. Alternativas para o controle de nematoides gastrintestinais de pequenos ruminantes. Arquivos do Instituto Biológico, 80(2), 253-263, 2013. Disponível em: http://www.scielo. br/pdf/aib/v80n2/18.pdf
Moraes, M. I. La producción de lanas en el Uruguay contemporáneo: Una visión de largo plazo. In: Piñeiro, D. Trabajadores de la esquila: Pasado y presente de un oficio rural. Montevideo: CSIC, 2003.

Mota, M. A; Campos, A. K; Araujo, J. V. Controle biológico de helmintos parasitos de animais: estágio atual e perspectivas futuras. Pesquisa Veterinária Brasileira, 23(3), 93-100, 2003.

Nahum, B. La época batllista 1905-1929. Montevideo: Banda Oriental, 2007.

Narbondo, I.; Paparombarda, I.; Sancho, D. Las estrategias de apoyo a la producción desarrolladas por la Asociación de Productores Lecheros de San José: Estudio de impacto sobre la sustentabilidad de sistemas familiares lecheros. Montevideo, Trabalho de Conclução de Curso (Ingeniero Agrónomo) - UDELAR, 2010.

Nari, A. The prevalence of anthelmintic resistance in nematode parasites of sheep in Southern Latin America: Uruguay. Veterinary Parasitology, 62, 213-222, 1996. doi: 10.1016/0304-4017(95)00908-6

Nery, P. S.; Duarte E. R.; Martins, E. R. Eficácia de plantas para o controle de nematóides gastrintestinais de pequenos ruminantes: revisão de estudos publicados. Revista Brasileira de Plantas Medicinais, 11(3), 330-338, 2009. doi: 10.1590/S1516-05722009000300016

OMS - Organización Mundial de la Salud; FAO - Organización de las Naciones Unidas para la Agricultura y la Alimentación. Codex Alimentarius: Alimentos Producidos Orgánicamente, Tercera edición, 2007. Disponível em: $<$ http://www.fao.org/docrep/010/a1385s/a1385s00.htm>. Acesso em: fev. 2015.

Oliveira, L. N.; Duarte, E. R.; Nogueira, F. A.; Silva, R. B. da; Faria Filho, D. E. de; Geraseev, L. C. Eficácia de resíduos da bananicultura sobre a inibição do desenvolvimento larval em Haemonchus spp. provenientes de ovinos. Ciência Rural, 40(2), 488-490, 2010. doi: 10.1590/S010384782009005000254

Oreggioni, W. Estrategias contratendenciales de la Sociedad de Fomento Rural la Casilla (Flores, Uruguay) para promover la sustentabilidad de sus productores familiares lecheros. Montevideo, Dissertação (Magister en Ciencias 
Agrarias) - UDELAR, 2011.

Oyhantçabal, G. Evaluación de la sustentabilidad de la producción familiar de cerdos a campo: Un estudio de seis casos en la zona sur del Uruguay. Montevideo, Trabalho de Conclução de Curso (Ingeniero Agrónomo) - UDELAR, 2010.

Oyhantçabal, G. Los tres campos en la cuestión agraria en Uruguay. Revista NERA, 22, 2013. Disponível em: http://revista.fct.unesp.br/index.php/nera/article/viewFile/1881/2266

Pinheiro Machado, L. C. Pastoreo Racional Voisin: tecnología agroecológica para el tercer milenio. Buenos Aires: Hemisferio Sur, 1. ed., 2011.

Pinheiro Machado, L. C.; Pinheiro Machado Filho, L. C. A dialética da agroecología: Contribuição para um mundo com alimentos sem veneno. São Paulo: Expressão Popular, 1. ed., 2014.

Piñeiro, D. Formas de resistencia de la agricultura familiar: el caso del Noreste de Canelones. Montevideo: CIESU/ Banda Oriental, 1985.

Piñeiro, D. La agricultura familiar: el fin de una época. In: Piñeiro, D. (Ed.). Nuevos y no tantos: Los actores sociales para la modernización del agro uruguayo. Montevideo: CSIC, p.147-198, 1991.

Puerto Abreu, M.; Arece García, J.; López Leyva, Y.; Roche, Y.; Molina, M.; Sanavria, A.; da Fonseca, A. H. Efecto in vitro de extractos acuosos de Moringa oleifera y Gliricida sepium en el desarrollo de las fases exógenas de estrongílidos gastrointestinales de ovinos. Revista de Salud Animal, 36(1), 28-34, 2014. Disponível em: http://scielo.sld.cu/scielo.php?script=sci_arttext\&pi$\mathrm{d}=$ S0253-570X2014000100005\&lng=es

Ramírez-Restrepo, C. A.; Barry, T. N.; Lopez Villalobos, N.; Kemp, P. D.; Pomroy, W. B.; Mcnabb, W. C.; Harvey, T. G.; Shabolt, N. M. Use of Lotus corniculatus containing condensed tannins to increase lamb and wool production under commercial dryland farming conditions without the use of anthelmintics. Animal Feed Science and Technology, 117, 85-105, 2004. doi: 10.1016/j.anifeedsci.2004.05.005

Ramírez-Restrepo, C. A.; Barry, T.N.; Pomroy, W. E.; Ló-
pez-Villalobosa, N.; McNabb, W. C.; Kemp, P. D. Use of Lotus corniculatus containing condensed tannins to increase summer lamb growth Ander commercial dryland farming conditions with minimal anthelmintic drench input. Animal Feed Science and Technology, 122, 197-217, 2005. doi: 10.1016/j.anifeedsci.2005.03.009

RAU - Red de Agroecología del Uruguay. Normas de producción para la agricultura ecológica: Cultivos, recolección de silvestres y producción animal, 2006. Disponível em: $<$ http://redagroecologia.uy/wp-content/uploads/2014/12/ Normas-cultivos-y-animal.pdf $>$. Acesso em: jan. 2015.

Rodríguez Gatti, F. Estudio comparativo de los sectores horticola organico y ganadero organico en Uruguay. Montevideo, Trabalho de Conclução de Curso (Ingeniero Agrónomo) - UDELAR, 2010.

Schuch, L. F. D. Plantas medicinais em atenção primaria veterinaria: atividade microbiana frente a bacterias relacionadas com mastite bovina e a dermatófitos. Porto Alegre, Tese (Doctor em Ciencias Veterinárias) - UFRGS, 2007.

Sevilla Guzmán, E. (Coord.). Canales cortos de comercialización alimentaria en Andalucía, 2012. Disponível em: <http://www.juntadeandalucia.es/export/drupaljda/ CCC_alimentaria_en_Andalucia_2012.pdf $>$. Acesso em: sep, 2017.

Sevilla Guzmán, E. La participación en la construcción histórica latinoamericana de la Agroecología y sus niveles de territorialidad. Política y Sociedad, 52(2), 351-370, 2015.

Souza, M. M. C.; Bevilaqua, C. M. L.; Morais, S. M.; Costa, C. T. C.; Silva, A. R. A.; Braz-Filho, R. Anthelmintic acetogenin from Annona squamosa L. Seeds. Anais da Academia Brasileira de Ciências, 80(2), 271-277, 2008. doi: 10.1590/ S0001-37652008000200005

SUL - Secretariado Uruguayo de la Lana. Cordero pesado SUL: Carne ovina con sello de calidad. Montevideo: SUL, 1999.

Thorne, P. J.; Tanner, J. C. Livestock and nutrient cycling in crop-animal systems in Asia. Agricultural Systems, 71, 111-126, 2002. doi: 10.1016/S0308-521X(01)00039-7

Tommasino, H. Sustentabilidad Rural: desacuerdos y controversias. In: Pierri, N.; Foladori, G. (Ed.). ¿Susten- 
tabilidad? Desacuerdos sobre el desarrollo sustentable. Montevideo: Trabajo y Capital, p. 139-163, 2001.

Torres-Acosta, J. F. J.; Mendoza-de-Gives, P.; Aguilar-Caballero, A. J.; Cuéllar-Ordaz, J. A. Anthelmintic resistance in sheep farms: Update of the situation in the American continent. Veterinary Parasitology, 189, 89-96, 2012. doi: 10.1016/j.vetpar.2012.03.037

Uruguay. Decreto n. 557/008 de 17 de novembro de 2008. Crea el Sistema de Certificación de la Producción Orgánica. Disponível em: $<$ https://www.mgap.gub.uy/dgssaa/Normativa/Archivos/NUEVOS/Decreto_organicos.pdf $>$
Uruguay. Lei n. 19.292, de 24 de dezembro de 2014. Declara de interés general la produccion familiar agropecuaria y pesca artesanal, estableciendo un mecanismo de reserva de mercado estatal de bienes y servicios alimenticios. Disponível em: <http://www.parlamento.gub.uy/leyes/ AccesoTextoLey.asp?Ley=19292\&Anchor=>

Zacharias, F.; Guimarães, J. E.; Araújo, R. R.; Almeida, M. A.; Ayres, M. C.; Bavia, M. E.; Mendonça-Lima, F. W. Effect of homeopathic medicines on helminto parasitism and resistance of Haemonchus contortus infected sheep. Homeopathy, 97, 145-151, 2008. doi: 10.1016/j.homp.2008.05.004 